\title{
The Role of Mass Media in Establishment of Political Endeavor
}

\author{
Ghafar Zaeri \\ A member of academic fellowship, faculty of political sciences, Islamic Azad University, \\ Lamerd Branch
}

Corresponding Author E-mail: ghafarzarei@yahoo.com

Received: 24 October 2018, Revised: 05 December 2018, Accepted: 20 December 2018

\section{ABSTRACT}

Realization of Political Endeavor requires mass media to play an appropriate and optimal role in the field of communication and raising people's political information level. As an independent variable, mass media have direct and undeniable impact on establishment of political endeavor (Institutionalism) as a dependent variable. Direct and indirect role of mass media in institutionalism of political endeavor leads to national political correlation and spreading participative political culture. As messengers and interpreters of various dimensions and perspectives of political endeavor, mass media are considered as an effective factor toward political convergence and integration within the System of Islamic Republic of Iran. The culture-inspiring effects of mass media may cause political dichotomy, discord, and gaps to reduce and to convert approach of political endeavor into a platform for political integration and correlation in the community. Mass media may convey concepts and idea of political endeavor to political and social body of the society. Software capability of mass media causes effectiveness, potential, and legitimacy of political system. The present research mainly intends to study the role of mass media in establishment of political endeavor. Creation and development of political stability, prevention from intersystemic crises and conflicts, improvement of political participation culture are some of cultural and political potentials of mass media. The main question of this investigation is: What impact do mass media exert on political endeavor? Research hypothesis denotes that mass media may play an effective role in political endeavor. The major objective of this study is the interpretation and description of the relationship between variables of mass media and political endeavor.

Keywords: Media, Political Endeavor, Institutionalism, Iran.

\section{Introduction}

As a political method and culture, originated from sociopolitical culture in political system of Islamic Republic of Iran, political endeavor and its institutionalism requires the tools for its realization and establishment by mass media. At the 
beginning of Iranian new calendar year 1392 (2013), Supreme Leader called this year as Year of Political and Economic Endeavor. Focusing on political endeavor and its relevant concepts, the current study tends to describe various dimensions and perspectives of political endeavor and it refers to role of mass media in realization and institutionalism of political endeavor. The role, which is played by mass media in the field of Iranian sociopolitical developments, particularly to make political endeavor salient as a political technique, is crucially important toward spreading and developing political participation. Since $20^{\text {th }}$ and $21^{\text {st }}$ centuries, mass media are called the fourth cornerstone of democratic governments. Through expansion and development of modern Information and Communication Technologies (ICTs) in new era, the information and events are transferred to citizens of the countries at the moment. The impact and volume of data transfer in today world, especially in developed countries, are to the extent that some experts call it Media Imperialism (Giddens, 2006). Information and communication control and its impact on public opinion within the nations, add to the importance of role and efficient position of mass media. With development and expansion of various types of communication and media tools such as radio, TV, book, theatre, press (newspaper and journals), satellite and internet, one should always seek for this fact that how mass media affect climate of political endeavor in the system of Islamic Republic of Iran. What is the impact of mass media on institutionalism of political endeavor? By encouraging participatory and motivational political culture, can mass media strengthen the political and epic culture with the society? Each of mass media should be employed to select, classify, and prioritize in political news and analysis based on media relevant goals, missions, and interests. Some experts like Wilbur Schramm call it filter. Some others use the concpt of selection. Kurt Lewin utilizes the concept of Gatekeeping for this purpose (Boroujerdi Alavi, 2001). Although political system in Islamic Republic of Iran may provide the ground for developing mass media, the media should practically demonstrate their own positive role as a part of the social system as a whole. Contribution to political endeavor institutionalism is one of the parameters for proving such performance. Such an approach requires no exaggeration and overemphasis. There are three relationships between media and politics in terms of effect, affection, and interaction. According to a theory (C.N.N), Media may affect Politics. Based on the theory of producing agreement and theory of elites, politics influences media and at last the interactive theory. It is argued that there is a mutual relationship between media and politics. Rather than accepting some theoretical capabilities and empirical findings of theory of agreement production, in interactive theory of media and power it is believed that it should form two-way flow between news media and political power (Entekhabiand Heirannia, 2010). The role, which media play in growth and establishment of political endeavor, is one of the positive characteristics of their performance in Islamic Republic of Iran. This survey aims at the role of mass media in institutionalism of political endeavor through establishment of relationship between these two variables. Media software performances in Iran should deal with reconstruction of fresh political climate toward realization of political 
peaceful participation culture with focus on political endeavor as a pivot.

\section{Mass Media}

Mass media and data transfer are some close concepts so that they generally account for communications and mass relations. Mass media are a tool for developing and establishment of human relations. Mass media are meant to transfer and establish relation among public field and political power field. This process in communication science (IT) is interpreted as mass communication. Mass media are a device that has been noticed by an enormous group of people (Kazno,1999). Mass media are briefly divided into two groups : The first includes printing and writing instruments like journals, magazines, and books etc and the other is audiovisual devices such as radio, $\mathrm{TV}$, satellite and the internet. Among these devices, three political communication devices including TV, radio, and newspaper have drawn more attention of politicians and political practitioners (Rohani, 2007). Mass media are sources of data collection and distribution in various social fields. The large limit of their information flow has caused the subject of quality of communication and superiority of their media- related goals and activity to be noticed by experts. The superior medium or media have some characteristics as follows: First, the superior medium possesses adequate comprehensiveness, speed, and accuracy in publishing news and events. Secondly, the preferred medium is audienceoriented, culture-making while believing in religious principles and bases with disambiguating nature. Thirdly, unlike joint stock companies which rely on their shareholders, media are not owned by the governments. At fourth place, creating interaction between individuals and groups and structure is one of their basic tasks (Nejatbakhsh Esfahani and Bagheri, 2008). Rather than the features of superior media which are defined in the field of interaction, culture- making, information totality, and political independence, the media may be noticed in terms of their impact on sociopolitical institutions in one hand and transferring political peaceful values and norms on the other hand. Thus, mass media may highly affect qualitative growth of data flow by means of two elements of message and communications. With introducing internet, a revolution has occurred in the field of information freedom throughout the world since before emerging of internet, mass media dealt with selection of messages and their quality control and in fact theories and ideas (especially in political field) were imperfectly transferred to people via radio, TV, and newspapers. However, after introducing new communication technologies, the user could receive immediately and directly the writers' comments and views from them. Internet media have penetrated into cellular (mobile) world by means of digital technologies like iPad and iPhone. To raise enthusiasm for elections and establishing relationship with a large group of educated people and acquainted with modern technologies, mass media show their special consideration (Eivazi, 2009). Employing all capacities of mass media is a strong and effective tool for realization and establishment of political endeavor. It may convert political threats, destructions, and challenges into opportunity and success. Technologies, skills, and innovations are some constituent layers of culture. They witness a modern environment and climate on which public culture forms and they are considered as symbol of interaction and exchange of social actions and behavioral models 
(Dehshiri, 2009). Anywhere including Iran, mass media have three main applications including communication, critique and correlation among various views and tastes. Andrew Heywood emphasizes three performances of mass media: 1) Communication with citizens to form their thoughts; 2) Critique and regulations over ones who are in power; and 3) Gathering and identifying the agents with several thinking styles in the community (Heywood, 2007). In political field particularly political endeavor, media performances are formed in such a way that media contribute to activation of potential capacities of political governance in Islamic Republic of Iran through description of advantages and pathology of its defects in political filed.

\section{Political Endeavor}

The world endeavor means bravery and gallantry. This word has more extensive meaning than its lexical concept in political field. The emphasis of the Supreme Leader of Iran on this concept may signify a political movement for realization of the maximum presence of people in all scenes of Islamic Revolution of Iran. Political endeavor is the interpretation of a political movement in order to smooth legal and peaceful participation by all tastes and loyal groups in Islamic Republic of Iran. Political endeavor is seen as maximum presence of people in elections forum. Such a maximal presence does not mean populism but it is the evidence for the existing the maximum attentive participation of people in determination of their own political fate. Political endeavor has arisen from dialogue of Islamic Revolution. In daily language and terminology, dialogue stands for contact, talking, and speech conversation. In technical meaning, dialogue is a certain system of knowledge in the given language and it has been characterized as a certain mental state that structuralizes perception and behavior. In fact, theory of dialogue reveals intuitive intention of goals and performances (Heywood, 2008). Any type of speech, expression, and writing is considered as a social flow that possesses social essence, substance, structure. Dialogues vary based on time and place and there are several dialogues in any country. Moreover, dialogues vary from a country to country... Dialogue as a certain field of lingual application may be identified by the aid of institutions and facilities to which dialogues are related and at the same time based on position or situation from which a dialogue arises and also the stance or place that is considered for the speaker (McNeil, 1998). Political endeavor is micro- dialogue in dialogue vocabulary of Islamic Revolution so that with focus on republic nature of Islamic system it tends to realization of emerging participation among all people in political fate of their country. The realization of political endeavor is on all people, elites, intellectuals, and academic graduates' onus. It pertains to the point that realization of political endeavor may cause national correlation and authority of political governance. The presence of all political groups and focus on plurality of political groups lead to political growth and development and it may convert many crises and challenges, which are exposed to political system, into opportunity and thriving. Political endeavor occurs in Iran when we witness the unification between elites and rational presence of people in elections. In interpretation of political endeavor, Supreme Leader considers elections as symbol of political endeavor. He argues that "The reputation of Islamic Republic of Iran is subjected to elections and people's presence before voting boxes and the effect of each of people on election 
of authorities of this country. Elections are a symbol of national will. It is a symbol of Islamic democracy. All political tastes and streams, who believe in Islamic Republic, shall participate in elections. All individuals, who believe in Islamic Republic and national independence and appreciate the future of this country and sympathize for national interests should participate in elections. Refusal from elections is only appropriate for those who oppose the Islamic System." The presence of all political groups in elections is a requisite condition but it is not enough. Political endeavor is reputable when it coincides with rule of law and respect for law by all citizens of the country. In this regard, Supreme Leader maintains that "Regarding subject of elections and otherwise, all people should surrender to the rule of law and observe it. Realization of political endeavor requires some measures and taking strategies, considering several aspects. The paramount instances of them are as follows: 1) Avoiding political exclusion (monopoly) and focusing on presence of all loyal groups to Islamic Republic; 2) Giving information and making the given culture for all people; 3) Creating correlation and prevention from disunitystimulating policies among political factions and groups; 4) Elites and political groups' avoiding marginal and trivial matters and dealing with resolving macro and necessary problems of the nation; 5) Inclusive presence of people as the major cornerstones for Islamic Republic of Iran; and 6) Making media-centered culture for realization and establishment of political endeavor in public opinion among the people. All these cases provide passing through a historical and difficult phase. International conditions and some measures made by world nations against Islamic Republic of Iran have cause encountering several difficulties and restraints in the international arena.

\section{Institutionalism of Political Endeavor}

Institution is a dynamic and stable system of measures that regulate individual or collective behavior based on the generated rules and procedures (Heywood, 2008). Institutions are some processes, which form behavior of governmental agents and officials formally and/ or informally and affect their thoughts and plans and they are composed of left rules, traditions, norms, and established contracts in some of organizations (Abniki, 2007). In better words, institution is referred to a group of efforts in the form of rules and regulations, which affect quality of behavior in some subjects that play a role or players of a common role or goal and require them to act within the accepted framework and structure. Institutionalism means the possessing of the models with adequate and stable potential and capability to tackle the exerted pressures on the system (Ghavam, 1994). To the extent that an institution may be secured from pressures, threats, and risks that raise the level of vulnerability by various methods and to be immunized from the violations caused by those risks, it has moved toward growth, development, thriving and reliability. Concerning institutionalism, some experts believe that "Institutionalism denotes a type of collective awareness in which members of the group may recognize the group as a reality with superior rights over their own rights. (LaPierre, 1996)". Samuel Huntington claims institutionalism as roaming procedure thereby the organizations and practical techniques may acquire value and stability. From his view, institutionalism level of any political organization or units may be determined by adaptation, complexity, independence, 
and integration of organizations and their method (Huntington, 1996). The autocratic and independent political institutionalism means emerging organizations and procedures, which are not exclusively reflected by interests of certain groups; for example, a party that represents interests of one group in the society so it should have independence less than a faction that integrates benefits and interests of several social groups (Bashiriyeh, 2008). Many political problems in the field of political participation and activities of political groups and actors in political sovereignty of Islamic Republic of Iran are due to lack of institutionalism of political endeavor culture. Institutionalism of political endeavor may alleviate some problems caused by political instability. Thus, lack of healthy competition, which is considered as the main mechanism of freedom and religious democracy, makes political order unstable in one hand, and reduces its effectiveness on the other hand. Therefore, for institutionalism of political endeavor, rules of game should be transparent and effective for a stable and efficient community (Omidi, 2002). If political activity becomes the tools and instruments for domestic individuals and groups and typically leads to exertion of hostile and aggressive measures and moves toward expanding active political gaps so these consequences should be considered as superficial and rootless nature of political participation inside the community. If political endeavor has been stabilized in a community, rulers' will may be to the extent that they act as government and these are the institutional disciplines that exactly determine under what conditions the rulers' decisions could be deemed legal and reliable. Here rulers' will and concept of power are not considered the same and rulers' private will is distinct from their common role so that all of their actions will not be recognized as permissible by institutions (LaPierre, 1996). One of the important characteristics of institutions and institutionalism of political endeavor is that there is a distinction and difference between limits of personal behaviors and actions of elites and institutional disciplines. Beyond personal views, attitudes, and votes, institutionalism of political endeavor is a group of powerful elites.

\section{Mass Media and Political Empathy}

Some experts like Wilbur Schramm, with an optimistic attitude toward relationship between mass media with national development in Developing Countries, acknowledged that mass media may participate in the rate and types of information which has been available for the people in developing countries. Mass media may extend horizons and contribute to conveying thought and enhance the level of individual and local thinking (Schramm, 1961). With respect to role of mass media in modernization and creating empathy (solidarity) in the society, Daniel Lerner argues that media- centered systems have flourished in some communities that are modern in terms of other criteria and on the other hand no modern society will not usefully act without a developed media related system (Lerner, 2004). Moreover, through dividing public communications into media and oral types, Daniel Lerner implies: "In media- centered systems, the main stream of public information is activated by a group of messengers, having been selected based on skilloriented criteria and their occupation is to transmit mainly descriptive messages (news) via non- private mass media (radio, movie, and publication) to audiences and in verbal systems, public information is 
issued in oral systems from the sources, which in terms of position in social hierarchy i.e. criterion (position) instead of the other criterion (skill) that permits them to have conversation while their content is mainly prescriptive to descriptive type (lerner, 2004)." As a developing community, Iran possesses both types of media- centered and oral systems in communication field and circulation of information. But media communication approach and motion are developing and expanding and it will act as a dominant communicative paradigm and play its role and performance nearly in the future. The various and multiple roles and performances of public and private media in any group, party, and organization, including political, cultural, economic, and social ones may encourage participation and competition to take advantage of these facilities so as to achieve more success in training its members and adherents, promotion and developing influence rather than prompting communication. Media form Iranian sociopolitical developments, especially political endeavor, so great that at present time, some concepts like national security, geographic borders, legal and cultural governance are subjected to transformation and change (Mansour, 1997). In Iranian society, the existing different ethnicities, various climatic conditions, several customs and rites, religious and traditional different attachments, various financial and social classes and so forth are obvious and natural and under such conditions the vital role of TV and other mass media with vertical distribution system order may be revealed well in homogeneity of comments from all various tastes and their role in filling the gaps. Taking such an approach of culture may justify making mass media to provide the platform for institutionalism of political endeavor within political empathetic climate.

\section{Normative Media and Political Endeavor}

Normative media mainly include some types of media, which follow technical and professional rules and ethics in description and interpretation of news and information. Institutionalism of political endeavor is indebted to growth of such media in system of Islamic of Republic of Iran. If we consider these values as have-to and have-not-to and norms that mean behavioral models derived from the given values, then we may conclude that what it deemed as important in culture of political endeavor is value- driven action by mass media. At the same time, value- driven action is subjected to cultural, political, social, and economic frameworks so it also deals with a reasoning method including empirical, analytical, interpretive methods to reproduce and compose thoughts. Value-driven action is the stimulant and rational element of socio-cultural system (Chalapi, 1996). Mass media may be efficient if adapted to cultural and social values of the community in process of political sociability and improvement of statuses. Colin argues that in the process of political sociability in terms of influence of mass media, four communication elements should be taken into consideration including sender of message, message content, message transmission device, and receiver of the message (Ghavam, 1995). Political sociability is one of the important applications of mass media that contributes to individual identification and possibility for communication between the person and political system. The medium is similar to a teacher or mentor, who improves methods and techniques of political recognition of people toward ruling cornerstones and principles. On the 
other hand, it contributes to enhancement of political correlation with training political norms and values. The political communication fields deal with the connection between parties and leaders of community with people, communication among political groups, connection between peoples' requests and goals of politicians as well as relationship among parties and people (Dadgaran, 2009). Emphasis on improving political endeavor is the best way of normalization of mass media. This method leads to national solidarity and unity and encourages culture of political endeavor to a common sense and sense of belonging among political groups for convergence inside political structure. Mass media are stemmed from sociopolitical structure in one hand, and they contribute to reformation and refinement of this structure on the other hand. Some practices like establishing of order, valuedriven tendency, avoiding insulting and accusation, preservation of national authority and security, and political development of the system are deemed as the performances of normative and standard media that emerge within valuedriven thinking framework. In any political system, mass media act based on the known rules and norms, varying from a system to another one. In Article 24 of Iran's Constitution, it has been explicitly expressed that periodicals and press are free to express the news unless that news creates disorder and disruption in Islamic fundamentals or Common Law. Its details are determined by law (Mansour, 1997). Law of Mass Media in Iran is originated from Islamic system and sociopolitical security. With respect to political and ideological norms, teachings, and fundamentals of the society, activity of mass media and quality of their action are consistent with these standards. Although nature and relationship of media and policy may differ from one society to another, Sara Oates has tried to interpret general and comprehensive criteria in this field with the purpose of a model for news production including political setting, media related rules and regulations, media ownership, professional norms for journalists and rate of developing industry of Public Relations (Oates, 2008). It is obvious that the characteristic of media in Iran may be perfectly complied with the given criteria. According to sociopolitical capacities and potentials in any society, political environment, framework of rules, norms and regulations based on which the media deals with political activity could be explained. The characteristics of politics and political elites in Iran and quality of their political action and its relationship with mass media are measured accordingly. There is a bilateral relationship between institutionalism of political endeavor and media. With creating the possibility for exchange of data among people and government, mass media guarantee the performance of principles of religious democracy. By these media people can be informed about government's efforts and at the same time government may be aware of citizens' interest. This two-way information stream as well as freedom of media to play regulatory role of people is not too important at any time except for period of holding elections. At this period, media are highly active to broadcast political events. Written media may allocate the columns of periodicals to reporting news, analyses, editorials, and comments of other bodies. Radio and TV deal with broadcasting news and analytical programs, elections panel discussions and promotional programs from factions and their candidates. Parties and candidates try to attract attention of mass media as one of the basic methods to 
access to voters (Shakeri, 2005). Under such circumstances, if the role mass media is not originated from a pragmatic and rationalist attitude in the field of communication and quality of political news and events analysis so political arena may be turned into a field of confrontation and conflict between political groups. The worst way of communication is when mass media convey information and news to political elites based on their partyfactional interpretation and expression and far from the existing realities in the community. Words and lexicons may be much more dangerous than bombs and ballots. They may cause political unrest (Mac Nair, 2008). Mass media should contribute to reduction of political gaps between political groups and government through following up the moderation and rationalist policy and avoiding sending discord- creating messages and they should provide the ground for national political correlation to realize political endeavor with focus on normative- ethical model. Realization of such policies through mass media is subjected to sense of responsibility for political affairs in the country, recognition of the position of jurisprudent's governance in Islamic system, identifying political plots by enemies of Islamic Revolution, paying attention to elections and doing electoral duty with respect to Supreme Leader's guidelines, developing people's political information and preserving empathy among people and political system turning around pivot of leadership.

\section{Conclusion}

As a strategic approach toward the allinclusive presence of people in political, social, and economic arenas, political endeavor requires improvement, continuance, and establishment in public opinion. Putting ICT and technologies of transferring news and data to public opinion at their disposal, mass media play a crucial role in internalization of this political thought. Dialogue of Islamic Revolution with institutionalism of political endeavor culture is converted into an important model of Islamic political culture among other Islamic Nations. Adopting this model by political factions and groups in the country can make it a model of political participation culture and support for national sovereignty and security. Political endeavor needs planning by media and socio-cultural propaganda toward identifying the advantages and pathological analysis. Due to nationalreligious feature and local- domestic values, political endeavor may be converted into an appropriate paradigm and model out of political participation model for the people not only for period of elections but for all times and opportunities in system of Islamic Republic of Iran. Mass media should manifest and establish parameters of political endeavors with respect to culture of moderation, Islam- orientation, religious democracy, Islamic leadership- centered (Velayat) culture as well as Islamic devotion- spiritual values and improving national correlation. Political endeavor should be observed through mass media as a national model and beyond factional and party-related limit and its domain should be extended.

\section{References}

Abniki, H. (2007). Institutionalist approach toward political decision making process, Journal of Domestic Policy, 1(2): 9-33.

Amir Entekhabi, S.H, Heirannia, J. (2010). The role of media in political participation of citizens, Researching Journal of Strategic Studies Researching Center, 50: 63-94. 
Bashiriyeh, H. (2008). Barriers against political development in Iran, Tehran: Gam Pub.

Boroujerdi Alavi, M. (2001). What is gatekeeping and who are gate-keepers? Collection of essays from professional journalists, Tehran: media studies and researches center.

Chalapi, M. (1996). Sociology of order, Tehran: Nashr-E-Ney Pub.

Dadgaran, M. (2009). The fundamentals of mass communications, Tehran: Morvarid Pub.

Dehshiri, M. (2009). Media and culture making, Quarterly of cultural researches, 2(4):179-208.

Eivazi, M.R. (2009). The effect of media on electoral behavior, Quarterly of communication researches, 16(57):157174.

Ghavam, A. (1994). The comparative policies, Tehran: SAMT Press.

Ghavam, A. (1995). The critique on theories of political reconstruction and development, Tehran: Publication of Shahid Beheshti University.

Giddens, A. (2006). The sociology, Transl. Saboori, M, Tehran: Nashr-E-Ney Pub.

Heywood, A. (2007). Politics, London: Palgrave Macmillan.

Heywood, A. (2008). Key concepts in politics, Transl. Saeed Kolahi, H, Kardan, A, Tehran: Scientific and cultural publication Inc.

Huntington, S. (1996). Political order in changing societies, Transl. Salasi, M, Tehran: Nashr-E-Elm.
Kazno, J. (2008). The sociology of mass media, Transl. Sarookhani, B, Mohseni, M, Tehran: Ettelaat Press.

LaPierre, J. (1996). Political power, Transl. Naderzad, B, Tehran: Forouzan Pub.

Lerner, D. (2004). Passing through traditional community, reconstruction in Middle East, Transl. Khajeh Sarvi, Gh, Tehran: Strategic Studies Center.

Mac Nair, B. (2004). The sociology of journalism, Transl. KIA, A.A. Rasooli, M, Tehran: Jameehshenasan Pub.

Macdonell, D. (1998). An introduction to theories on dialogue at the end of 1960s, Transl. Nozari, H, Sociopolitical quarterly of dialogue (Gofteman), 1(2):25-58.

Mansour, J. (1997). IRI Constitution, Tehran: Nashr-E-Doran.

Nejatbakhsh Esfahani, A, Bagheri, A. (2008). The role of mass media in prevention from crises, Quarterly of communication researches, 15(56): 137159.

Oates, S. (2008). Introduction to Media and politics, London: Sage publication.

Omidi, A. (2002). The role of healthy political competition in national establishment and loyalty, A collection of essays concerning political competitions and challenges in today in Iran, Tehran: Culture of dialogue.

Rohani, H. (2007). Mass media and national security, Monthly of strategic studies, 46: 7-34.

Schramm, W. (1961). Mass media and national development, Stanford: University Press. 
Shakeri, M. (2005). Mass media and Research Center.

presidential elections, Qom: IRIB Islamic

How to cite this article: Ghafar Zaeri, The Role of Mass Media in Establishment of Political Endeavor. International Journal of Advanced Studies in Humanities and Social Science, 2019, 8(4), 310-320. http://www.ijashss.com/article_84379.html 